\title{
Climate change and vine training systems: the influence different spatial distribution of shoots may have on sugar accumulation in Sangiovese grapevines.
}

\author{
Gabriele Valentini", Gianluca Allegro, Chiara Pastore, Emilia Colucci, Eugenio Magnanini and Ilaria Filippetti \\ Department of Agricultural and Food Sciences DISTAL - University of Bologna, Viale Fanin 44, Bologna, Italy
}

\begin{abstract}
The choice of training system may influence vineyard efficiency in terms of light interception and water consumption, particularly in the current context of climate change. On this basis, during the 2017 season, Sangiovese potted vines were grown outdoors using two different training systems: guyot vertical shoot positioned system (C) and V-shaped open canopy (A). From the end of June until September, vine transpiration was continuously monitored by the gravimetric approach and at different times in the season, the leaf area, light interception, photosynthetic activity and stem water potential were measured. Grape yield and fruit composition were recorded at harvest. $\mathrm{C}$ plants did not differ from $\mathrm{A}$ in terms of leaf area during the entire season. Light interception was higher in $\mathrm{C}$ vines during the early hours of the morning and lower in the central part of the day and the transpiration loss was higher, as was the net photosynthesis detected on some days in August. No differences were detected in terms of yield but a significant increase in soluble solids was found in C compared to A. The open canopy compared to a closed one, in a particularly hot year like 2017, resulted in negative consequences on the accumulation of soluble solids, probably as a result of the radiative stress suffered by the A vines in the middle hours of the day.
\end{abstract}

\section{Introduction}

Water consumption by agricultural plants normally refers to all water evaporated from plant and soil surfaces plus that which is retained within plant tissues typically accounting for less than $1 \%$ of the total evaporated during a normal growing season [1]. Vineyard water loss is related to the amount of evaporative demand from the atmosphere and effective water consumption. The latter is greatly impacted by both training system and row orientation: vines with the same leaf area show different water consumption in relation to plant density [2;3]. Many studies have also highlighted how modifying the total amount and distribution of plant leaf area through the training system alters vine microclimate by affecting mainly light environment and leaf temperature. This impacts vine performance in terms of photosynthesis $[4 ; 5]$. On this basis, a two-year study conducted by [6] on potted vines revealed the effects of canopy restriction on total vine assimilation when the same foliage was first free to grow open and subsequently forced between containment wires. However, in recent years we have been witnessing a radical change in climatic conditions that show an alternation of diversified seasonal trends affecting mainly a rise in air temperature, a steady carbon dioxide concentration increase in the atmosphere and changes in rainfall distribution throughout the season and agricultural area $[7 ; 8 ; 9 ; 10]$. It has also emerged that in field conditions, vines are affected by multiple environmental stresses such as excessive light and temperature [11], leading to physiological and biochemical changes in plant growth and fruit composition [12]. In the context of climate change, the aim of this study was to evaluate, in potted Sangiovese vines, the relationship between two training systems with closed and open canopies - and leaf gas exchanges in terms of transpiration and photosynthesis, to obtain a model for the evaluation of water and light use efficiency.

\section{Material and methods}

\subsection{Plant material and Site description}

The trial was conducted in 2017 on 8 uniform potted Vitis vinifera L. cv. Sangiovese (clone 12T) grapevines grafted on SO4 rootstock at the Department of Agricultural and Food Sciences (DISTAL) of the University of Bologna (Italy). The vines were planted in 2010 in $30 \mathrm{~L}$ pots filled with a soil mixture $(39 \%$ sand, $39 \%$ silt and $22 \%$ clay) with an organic matter content of $1.8 \%$ and $\mathrm{pH}$ of 7.8 . Field capacity and wilting point were calculated after Saxton and Willey (2005) and set at $0.29 \mathrm{~cm}^{3} / \mathrm{cm}^{3}$ and $0.14 \mathrm{~cm}^{3} / \mathrm{cm}^{3}$, respectively.

\footnotetext{
Corresponding author: gabriele.valentini4@unibo.it
} 
The trial compared two training systems arranged on a single N-S oriented row: a Guyot vertical shoot positioned (C) and V-shaped open canopy grapevines (A) with a vine spacing of $1 \mathrm{~m}$ in the row. Each vine was pruned to two fruiting canes of 10 buds. The fruiting canes were $0.8 \mathrm{~m}$ from the ground: in $\mathrm{C}$ all the shoots were constrained in a trellising system consisting of two pairs of catch wires while in A the shoots were free to grow on two foliage wires on each side.

Trimming was not performed during the season and vines were provided with mineral nutrition according to vine yearly consumption. Throughout the growing season, air temperature and rainfall were monitored by an automatic meteorological station located near the vines.

\subsection{Vegetative and yield data}

Vine leaf area was estimated after determining the linear relationship between main and lateral shoots length $(\mathrm{cm})$ and corresponding leaf area $\left(\mathrm{cm}^{2}\right)$ for 10 shoots collected from extra vines. Leaf area was measured with a LI3000A leaf area meter (Li-Cor Biosciences, Lincoln, NE, USA). Regression curves (data not reported) were used to estimate leaf area on each vine by measuring the length of all main and lateral shoots.

At early veraison, (DOY 195) the site was monitored with a single flight survey at $30 \mathrm{~m}$ above ground level at solar noon by a UAV platform Highone4hsepro (Italdrone srl, Ravenna, Italy) equipped with a TETRACAM multispectral camera (Tetracam $\mu$-MCA, Tetracam Inc., CA, USA).

At harvest the collected data included, for both $\mathrm{C}$ and $\mathrm{A}$ : yield, bunch number and weight, berry mass, bunch compactness and rot incidence. Bunch compactness was assessed using the OIV 204 index (1-9 scale, OIV, 1993) and rot infection was expressed as percentage of infected area per bunch.

\subsection{Berry sampling and must composition}

At harvest (DOY 248) a sample of 20 berries per vine was collected by cutting through the pedicel with scissors. Each sample was immediately processed to determine must biochemical parameters. The soluble solids concentrations were detected using a temperaturecompensating Maselli R50 refractometer (Maselli Misure, Parma, Italy). Must $\mathrm{pH}$ and titratable acidity were measured using a Crison Titrator (Crison Instruments, Barcelona, Spain).

Subsequently, extra berry samples (20 berries), collected from each pot, were frozen and stored at $-80^{\circ} \mathrm{C}$ for total anthocyanins analyses via HPLC (Waters, Milford, MA, USA) following the method described by Mattivi et al. (2006).

\subsection{Light interception}

The fraction of light intercepted by each vine was estimated by taking below-canopy photosynthetically active radiation (PAR) readings with a ceptometer equipped with 34 sensors linked to a CR1OX dataIogger (Campbell Scientific, Inc., USA). The line sensor was moved on a below vine grid orthogonal to the canopies and data were recorded every $10 \mathrm{~cm}$ to get 10 scans per vine yielding a total of 340 individual light values. The effective measuring length of the line $(180 \mathrm{~cm})$ was sufficient to capture the entire ground-projected canopy shadow regardless of measurement time. The light readings were taken on DOY 180 and 207, four times a day: every two hours starting at 9:30 am. Light interception was calculated as 100 (total incoming light measured simultaneously outside the canopies by an elevated PAR sensor) minus the calculated fractional light transmission beneath the canopies.

\subsection{Vine water status}

For precise accounting of vine water use from budbreak (DOY 108) to harvest (DOY 248), individual daily gravimetric vine water loss (E) was continuously measured using a platform scale mod. LAUMAS (ABC Bilance, Campogalliano, Italy) placed underneath each pot. Pot masses were recorded every ten minutes using a CR1000 datalogger (Campbell Scientific, Inc., USA). Each pot surface was covered with a plastic film to avoid interference from rainwater and to minimize losses due to soil evaporation.

Each pot was refilled with 4Lday-1 distributed automatically using a drip irrigation system during hours of minimal transpiration.

Stem water potential ( $\Psi$ stem) was measured at midday on DOY 201, 215 and 241 on three shaded basal leaves per vine using a Scholander pressure chamber (Soilmoisture Equip. Corp., Santa Barbara, CA, USA).

\subsection{Leaf net $\mathrm{CO}_{2}$ assimilation rate}

Leaf net $\mathrm{CO}_{2}$ assimilation rate (An) of both basal and apical leaves were recorded on DOY 201, 215 and 241 using a Li-cor 6400 portable photosynthesis system (Licor Biosciences, Nebraska, USA). At each measurement, three primary leaves were sampled on the basal and apical part of shoots per vine. Readings were performed at 9:30 am and at midday under natural light and humidity conditions. The reference $\mathrm{CO}_{2}$ concentration was setup at $400 \mu \mathrm{mol} \mathrm{mol}-1$ in a cuvette.

\subsection{Statistical analysis}

All data were analyzed statistically by the mixed procedure available in SAS v9.0 (SAS Institute, Inc., Cary, NC, USA). Incidence values of rot were subjected to arcsin square root transformation before analysis. Treatment comparisons were analyzed using the Tukey test with a cut-off at $\mathrm{P} \leq 0.05$.

\section{Results and discussion}




\subsection{Weather conditions, canopy light interception and vine transpiration}

The 2017 season had high air temperatures like those that have characterized the last years in the Mediterranean area: spring was quite warm and summer was hot and dry (Table 1). In particular, maximum temperature of about $40{ }^{\circ} \mathrm{C}$ was reached in the first week of August (Fig. 1). Rainfall from the beginning of April to end of September was $261.2 \mathrm{~mm}$ and most fell in late September after harvest. Accumulation of GDD (1 April-31 October) was 2151. However, the season had very high total radiation and a low air relative humidity (data not shown), especially from July through August. We therefore speculate that the grapevines were subjected to a very high evaporative demand from the atmosphere.

Table 1. Average air temperature and total rainfall in 2017.

\begin{tabular}{|c|c|c|}
\hline & $\begin{array}{c}\text { Average Air T } \\
\left({ }^{\circ} \mathrm{C}\right)\end{array}$ & $\begin{array}{c}\text { Total Rainfall } \\
(\mathrm{mm})\end{array}$ \\
\hline April & 14.1 & 33.4 \\
\hline May & 18.4 & 55.8 \\
\hline June & 24.5 & 21 \\
\hline July & 25.8 & 8 \\
\hline August & 26.3 & 25.2 \\
\hline September & 18.3 & 117.8 \\
\hline
\end{tabular}

Evaluation of leaf area during the season showed no differences between the two training systems (Table 2): the total amount of leaves reached a maximum at the end of July (DOY 207) when the canopies were fully developed and then decreased some days following harvest (DOY 248).

Table 2. Total leaf area $\left(\mathrm{m}^{2} \mathrm{~m}^{-1}\right)$ of the closed canopy (C) and open canopy (A) vines in 2017. Different letters within a column indicate significant differences as calculated by the Tukey test $(\mathrm{p} \leq 0.05)$.

\begin{tabular}{|c|c|c|c|}
\hline & DOY 180 & DOY 207 & DOY 263 \\
\hline C & 1.4 & 1.9 & 1.4 \\
\hline A & 1.2 & 1.7 & 1.3 \\
\hline
\end{tabular}

To confirm that, the NDVI image obtained at early veraison (Fig.2) did not show significant differences between the two training systems and the mean values calculated for C and A were 0.629 and 0.625 respectively.

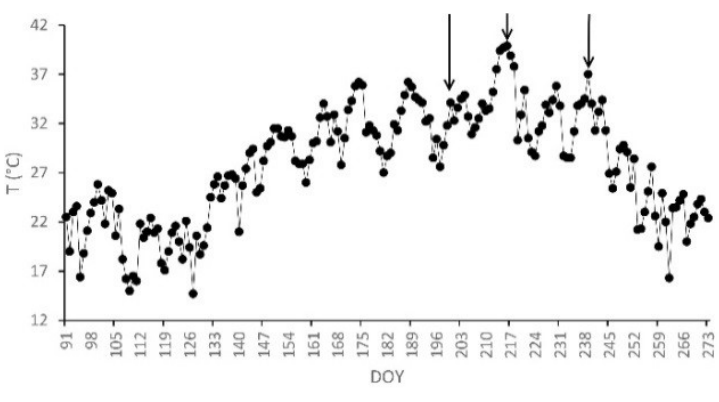

Fig. 1. Trend in maximum temperature (T) from April 1st (DOY 91) to September 30th (DOY 273) in 2017. Arrows indicate the date on which the gas exchange measurements were performed.

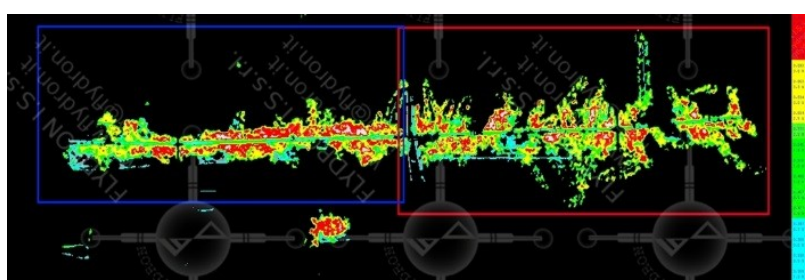

Fig. 2. NDVI image obtained at noon on 14th July (DOY 195). The different training systems are distinguished by blue (C) and red (A) rectangles. The palette indicates the NDVI values (0.300-0.900): light-blue for low vigor, green and yellow for medium and red for high vigor.

The light intercepted by the two training systems exhibited temporal patterns during the day (Table 3). In particular, $\mathrm{C}$ vines intercepted more light during the early hours of the morning. On the contrary, open-top A vines intercepted more light at noon as the leaves of the $\mathrm{V}$ system were more exposed to direct solar radiation due to the canopy architecture (Fig. 2). In the afternoon, no differences were recorded in terms of intercepted light between the two training systems in June (DOY 180) and July (DOY 207) (Table 3).

Table 3. Total light intercepted by the closed canopy (C) and open canopy (A) vines (\%) during the day on June $29^{\text {th }}$ (DOY

180 ) and July $26^{\text {th }}$ (DOY 207). Different letters within a

column indicate significant differences as calculated by the Tukey test $(\mathrm{p} \leq 0.05)$.

\begin{tabular}{|c|c|c|c|c|c|}
\hline DOY & & $\begin{array}{c}9: 30 \\
\mathrm{am}\end{array}$ & $\begin{array}{c}12: 30 \\
\mathrm{am}\end{array}$ & $\begin{array}{c}14: 30 \\
\mathrm{pm}\end{array}$ & $\begin{array}{c}16: 30 \\
\mathrm{pm}\end{array}$ \\
\hline \multirow{2}{*}{180} & $\mathrm{C}$ & $42 \mathrm{a}$ & 26 & $6 \mathrm{~b}$ & 21 \\
\cline { 2 - 6 } & $\mathrm{A}$ & $33 \mathrm{~b}$ & 23 & $17 \mathrm{a}$ & 23 \\
\hline \multirow{2}{*}{ DOY } & & $\begin{array}{c}9: 30 \\
\mathrm{am}\end{array}$ & $\begin{array}{c}12: 30 \\
\mathrm{am}\end{array}$ & $\begin{array}{c}14: 30 \\
\mathrm{pm}\end{array}$ & $\begin{array}{c}17: 30 \\
\mathrm{pm}\end{array}$ \\
\hline \multirow{2}{*}{207} & $\mathrm{C}$ & $50 \mathrm{a}$ & 24 & $6 \mathrm{~b}$ & 58 \\
\cline { 2 - 7 } & $\mathrm{A}$ & $30 \mathrm{~b}$ & 22 & $19 \mathrm{a}$ & 57 \\
\hline
\end{tabular}

It is well known that the vineyard water requirement at the same evaporative demand from the environment is related to the light intercepted by the canopy measured during the day [3]. In our study case, $\mathrm{C}$ showed higher 
light interception during the cooler hours of the morning, whereas A did in the warmest central hours of the day (Table 3). This situation impacts the physiological response of potted vines in terms of water loss due to transpiration.

The data in Figure 3 are representative of the hottest period of the season between the end of July and first week of August. With respect to the evaporative demand and vine physiology, transpiration ranged between 2 and 5 L plant-1 day-1 and the graph shows that the closed canopy vines consumed more water than open ones with the same leaf area (Fig.3).

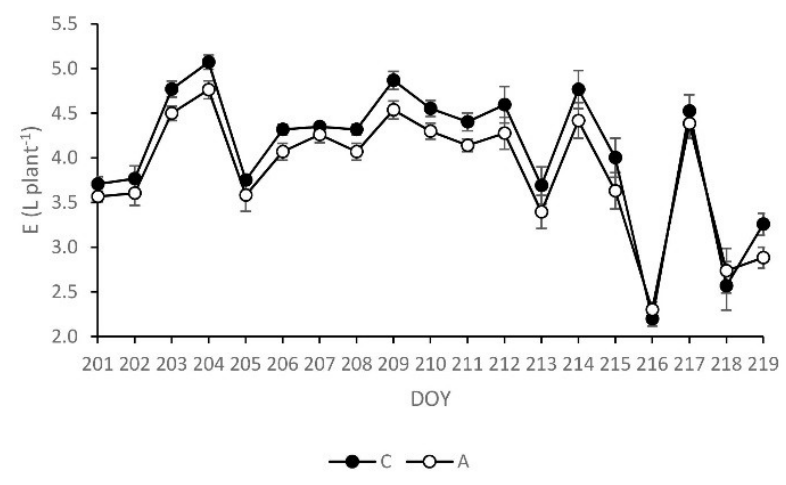

Fig. 3. Seasonal pattern of daily lysimeter transpiration in closed (C) and open (A) canopy vines. (E). Data are average of four vines \pm SE.

In more detail, the daytime trend of canopy transpiration during a typical August day of both $\mathrm{C}$ and $\mathrm{A}$ plants increased rapidly in the morning with the light intensity, reaching a maximum at $13.00 \mathrm{pm}$ (Fig. 4). Thereafter, the mean of $\mathrm{C}$ and $\mathrm{A}$ decreased. In particular, transpiration was greater for $\mathrm{C}$ before noon according to the higher percentage of leaves exposed to light (Table 3). Subsequently the two training systems showed a temporary decline in transpiration around 14:30 pm after which only $\mathrm{C}$ recovered in the afternoon. This data fits with the modeling outputs of daily light interception for a vertical grapevine canopy N-S exposed at the same latitude and time of year [15] and confirm the sensitivity of vine water loss to canopy orientation. Interestingly, under the conditions of this trial - characterized by high temperature - $\mathrm{C}$ showed a greater decline in transpiration than A during the central hours of the day as the sun's position was orthogonal to the soil and incoming light lost to the ground was at a maximum. After 15:00 pm, only $\mathrm{C}$ was affected by a temporary increase in water loss while a slight decrease in transpiration was observed in both $\mathrm{A}$ and $\mathrm{C}$ until nightfall. There are several studies on grapevines demonstrating that the amount of light intercepted by the canopy is important in determining whole vine water use [16; 17]. In particular, [18] reported that water use was higher in open hedgerow compared to compact hedgerow grapevine canopies.

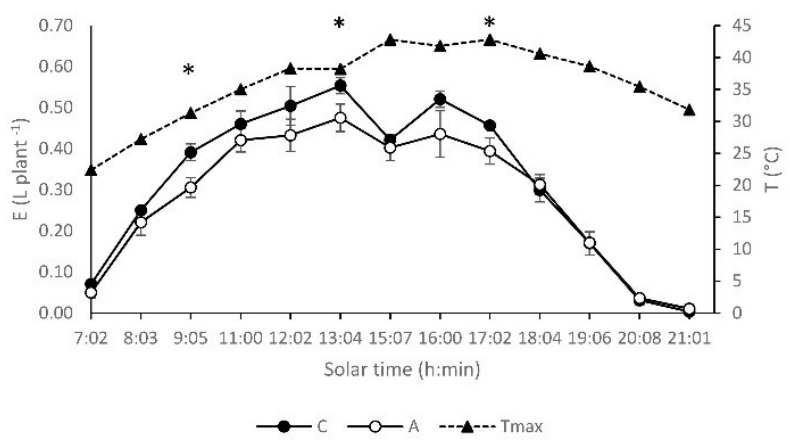

Fig. 4. Daytime trends of maximum temperature $(\mathrm{T})$ and canopy transpiration (E) during a typical August day in closed (C) and open (A) canopy vines. Data are average of three vine replicates \pm SE. Within each solar time, an asterisk indicates a significant difference between the two training systems as calculated by the Tukey test $(\mathrm{p} \leq 0.05)$.

On the contrary, in our trial under high temperature conditions, A never exceeded $\mathrm{C}$ in terms of transpiration even when it was exposed to more light.

\subsection{Vine water status and leaf assimilation rate}

It is well known that mean plant water status depends on water potential in soil layer, canopy size and evaporative demand [19]. In our research, the C and A vines were compared in the same environment and were supplied with water throughout the season. Although no significant differences were found between $\mathrm{C}$ and $\mathrm{A}$ stem water potential, it is evident that $\mathrm{A}$ reached the lowest values over the season (Table 4). Several studies established that stem water potential is an excellent indicator of grapevine water status based on solid correlation between $\Psi$ stem and leaf gas exchanges [19].

Table 4. Midday stem water potential ( $\Psi_{\text {stem }}$, bar) and leaf assimilation rate $\left(\mathrm{An}, \mu \mathrm{molm}^{-2} \mathrm{~s}^{-1}\right)$ in closed $(\mathrm{C})$ and open $(\mathrm{A})$ canopy vines. Measurements were taken on well exposed basal

and apical leaves for $A_{n}$. Each value is the average of four replicates. Different letters within a column indicate significant differences as calculated by the Tukey test $(\mathrm{p} \leq 0.05)$.

\begin{tabular}{|c|c|c|c|c|c|c|}
\hline & \multicolumn{2}{|c|}{ DOY 201 } & \multicolumn{2}{c|}{ DOY 215 } & \multicolumn{2}{c|}{ DOY 241 } \\
\cline { 2 - 7 } & $\Psi_{\text {stem }}$ & $\mathrm{A}_{\mathrm{n}}$ & $\Psi_{\text {stem }}$ & $\mathrm{A}_{\mathrm{n}}$ & $\Psi_{\text {stem }}$ & $\mathrm{A}_{\mathrm{n}}$ \\
\hline $\mathrm{C}$ & -7.6 & 7.8 & -7.3 & $11.3 \mathrm{a}$ & -5.7 & $5.3 \mathrm{a}$ \\
\hline $\mathrm{A}$ & -8.4 & 7.8 & -8.8 & $9.8 \mathrm{~b}$ & -6.3 & $4.5 \mathrm{~b}$ \\
\hline
\end{tabular}

In accordance with [20], we speculated that under conditions of high irradiance and vapor pressure deficit as at midday on clear and sunny August days - water flow into grapevines is insufficient to compensate for losses through transpiration, resulting in a midday depression of water potential. As a consequence, a decrease in stomatal conductance (data not reported) and net photosynthesis (An) were detected (Table 4) even under sufficient soil water availability, as reported by [21] and [22]. 


\subsection{Yield parameters and must composition at harvest}

The bunch number per vine was uniform (10 per vine) and yield, bunch mass, and berry mass were unaffected by training system. In regards to the health of the grapes, no differences were found for rot infection and no bunches were affected by botrytis or dryness (Table 5).

Table 5. Mean bunch weight, compactness, rot incidence, yield and leaf to fruit ratio $\left(\mathrm{m}^{2} / \mathrm{kg}\right)$ at harvest in closed $(\mathrm{C})$ and open (A) canopy vines. Different letters within a column indicate significant differences as calculated by the Tukey test $(\mathrm{p} \leq 0.05)$.

\begin{tabular}{|c|c|c|c|c|c|}
\hline & $\begin{array}{c}\text { Bunch } \\
\text { weight } \\
(\mathrm{g})\end{array}$ & $\begin{array}{c}\text { Bunch } \\
\text { compact } \\
\text { ness } \\
(1-9)\end{array}$ & $\begin{array}{c}\text { Rot } \\
\text { incidence } \\
(\%)\end{array}$ & $\begin{array}{c}\text { Yield/ } \\
\text { vine } \\
(\mathrm{Kg})\end{array}$ & $\begin{array}{c}\text { Leaf to } \\
\text { fruit } \\
\text { ratio } \\
\left(\mathrm{m}^{2} / \mathrm{kg}\right)\end{array}$ \\
\hline $\mathrm{C}$ & 90.3 & 5 & 0 & 0.93 & 1.54 \\
\hline $\mathrm{A}$ & 87.4 & 6 & 0 & 0.90 & 1.48 \\
\hline
\end{tabular}

Regarding must composition at harvest, while $\mathrm{pH}$ and total acidity were unchanged, the $\mathrm{C}$ training system achieved higher soluble solids (Table 6). The level of total anthocyanins was unaffected by training system (Table 6).

Table 6. Mean berry weight, soluble solids concentration, $\mathrm{pH}$, total acidity (TA) and total anthocyanins at harvest in closed

(C) and open (A) canopy vines. Different letters within a column indicate significant differences as calculated by the Tukey test $(\mathrm{p} \leq 0.05)$.

\begin{tabular}{|c|c|c|c|c|c|}
\hline & $\begin{array}{c}\text { Berry } \\
\text { weight } \\
(\mathrm{g})\end{array}$ & $\begin{array}{c}\text { Soluble } \\
\text { solids } \\
\left({ }^{\circ} \mathrm{Brix}\right)\end{array}$ & $\mathrm{pH}$ & $\begin{array}{c}\text { Total } \\
\text { acidity } \\
(\mathrm{g} / \mathrm{L})\end{array}$ & $\begin{array}{c}\text { Total } \\
\text { anthocyanins } \\
(\mathrm{mg} / \mathrm{kg})\end{array}$ \\
\hline $\mathrm{C}$ & 1.23 & $23.2 \mathrm{a}$ & 3.31 & 6.41 & 798 \\
\hline $\mathrm{A}$ & 1.05 & $21.8 \mathrm{~b}$ & 3.26 & 6.71 & 785 \\
\hline
\end{tabular}

In particular, the difference in sugar concentration can be ascribed to the different performance of $\mathrm{C}$ compared to A vines in light interception trend during the day and to the consequent higher photosynthetic activity. Further researches are required to understand the physiological mechanisms that have led open-canopy vines to accumulate less sugar and if this result could be linked to the particularly warm conditions of 2017 season.

\section{References}

1. M. E. Jensen, Water deficits and plant growth (1968)

2. L. E. Williams, XII GiESCO, Montpellier, pp 63-64 (2001)

3. L. E. Williams, J. E Ayars, Agr. Forest Meteorol. 132, 201-211 (2005)

4. R. E. Smart, Am. J Enol. Vitic. 24, 141-147 (1973)
5. S. Poni and C. Intrieri, Advance in Horticultural Science - JSTOR 15 (2001)

6. C. Intrieri, S. Poni, B. Rebucci, E. Magnanini, Vitis 36, 167-173 (1997)

7. H. R. Schultz, Aust J Grape Wine Res 6, 2-12 (2000)

8. M. Bindi, L. Fibbi and F. Miglietta, Eur. J Agron 14(2), 145-155 (2001)

9. E. Duchene and C. Schneider, Agron Sustain Dev 25, 93-99 (2005)

10. G. V. Jones Acta Hortic 932, 19-28 (2012)

11. R. Mittler, Trends in Plant Science 11, 15-19 (2006)

12. A. Palliotti, S. Tombesi, T. Frioni, O. Silvestroni, V. Lanari, C. D'Onofrio, F. Matarese, A. Bellincontro, S. Poni, J Plant Physiol. 185, 84-92 (2015)

13. K. E. Saxton and P. H Willey, In Watershed Models. D.K. Frevert and V.P. Singh (eds.) (Taylor \& Francis, Boca Raton, FL, 2005)

14. F. Mattivi, R. Guzzon, U. Vrhovsek, M. Stefanini and R. Velasco, J Agric Food Chem 54(20), 76927702 (2006)

15. E Magnanini and C Intrieri, Vignevini (1987)

16. C. Riou, P. Pieri, B. Le Clech, Vitis 33 (1994)

17. W. Trambouze, M. Voltz, Agr. Forest Meteorol. 107(2), 153-156 (2001)

18. J.L. Heilman, K.J. McInnes, R.W Gesh, R.J. Lascano, M. J. Savage, Agr. Forest Metereol. 81 (1996)

19. X. Chone, C. Van Leeuwen D. Dubourdieu, J.P. Gaudillère, Annals of Botany, 87(4), 477-483 (2001)

20. H.R Schultz, Plant, Cell Environ. 26, 1393-1405 (2003)

21. M. Gomez del Campo, P. Baeza, C. Ruiz and J.R. Lissarrague, Vitis 43 (3), 99-105 (2004)

22. J.M. Moutinho-Pereira, C.M. Correia, B.M. Gonçalves, E.A. BacelarJ.M. Torres-Pereira, Photosyntetica 42 (2004) 